\title{
Cross-disciplinary problem-solving workshop: a pedagogical approach to anticipate ergono- mist engineering design collaboration
}

\author{
Elisabeth Brunier, Michel Le Chapellier, Pierre Henri Dejean ${ }^{*}$ \\ Compiegne University of Technology (UTC) France \\ BP 60319-60203 Compiègne Cedex France
}

\begin{abstract}
The aims of this paper are to present concept and results of an innovative educational model approach based on ergonomics involvement in industrial project. First we present Cross disciplinary Problem solving Workshop by answering three questions:

1) What is a CPW: A partnership between Universities and one or several companies, purposes of it are first to increase health, well being, companies teams competencies, and competitiveness, second to train the "IPOD generation" to include risks prevention in design.
\end{abstract}

2) How does it work? CPW allows cooperation between experience and new insight through inductive methods. This model follows the Piaget (1) philosophy linking concrete world to abstraction by a learning system associating realization and abstraction

3) Is it successful? In order to answer this third question we will show examples of studies and models performed during CPWs.

It appears that the CPWs produce visible results in companies such as new process designs, new methods, and also changes in lectures. However some less visible results remain unclear: How the company personnel evolve during and after CPW? Does CPW motivate our future engineers enough to continuously improve their skills in risk prevention and innovative design?

\section{Introduction}

CPW is a 2 weeks intensive learning program mixing students and teachers from different curricula. CPW is made original by the combination of the following characteristics: Inductive, cross cultural and interdisciplinary, partnership between universities and companies, prevention of occupational risk and increase of well being, intensive (one or two weeks), from diagnostic to project, modeling. In this paper we will develop these original characteristics regarding the traditional learning system, then the more instructive results. Finally we will end by a discussion in order to harmonize this learning model with the traditional one, and by the suggestion of research ideas.

\section{Characteristics of CPW: An innovative learn- ing model}

\subsection{Partnership between universities and companies}

Companies belongs to the concrete world with specific features such as quick and efficient responses, financial constraints, project obligations to be understood and applied by every people, time constraints.

University open to the abstract world with other specific treat the need to refer to strong certitudes, to produce fundamental knowledge useful in different context ... The CPW is a short but intensive partnership between these two ways of acting, students and teachers are immersed (first week) in a company context (generally a factory) : the concrete world, and search to diagnostic the situation and solution

\footnotetext{
*Corresponding author: Pierre-henri-dejean@utc.fr
} 
using theoretical background and university facilities (second week). The shared goals are to improve educational efficiencies, increase health, well being, companies' team's competencies, and competitiveness.

\subsection{Prevention of occupational risk}

Very frequently the prevention of occupational risks is seen as a constraint: it would be a cost, and the no-compliance with the rules may result in fines, or punitive damages. But, many historical cases have shown that risk prevention also result in innovation. For example the necessity of the Royal Air Force of United Kingdom to reduce accidental losses has impulse the implementation of innovations that result from ergonomics; the threat of disease has been (and is) a innovations factor of medicine ... CPW is dedicated to identify innovations that both reduce occupational risks and improve competitiveness. For this reason, taking in account occupational risks in their study is a duty of students' teams.

\subsection{Inductive}

The students are confronted with an industrial reality that encompasses several occupational activities.

First, the students observe many technological and human aspects; listen some managers' speeches about the company, the activities, and some economics, technological and occupational issues.

Second, they shall identify (or recognize) problems related to this reality.

Third, they study the causes and the consequences of the identified problem, and consider alternative actions that could annihilate some of the causes or reduce some of the negative consequences.

Although many general principles has been developed using deductive methods (facts, events, subjects are first observed and studied, then used to generate ideas, and further laws or theories) the most current pedagogical practices at university is deductive: learn the rule first and then apply it. So many students don't immediately understand that are not asked to answer a manager's or teacher's questioning using a determined methods or a specific computer simulation, but they shall look and study the fact first, then identify a relevant issue and about it consider the opinions of teachers and of several stakeholders within the company, further develop an appropriate solution.
Since the students' team result embody a synthesis of employees' judgments the CPW method look like a bottom up method.

\subsection{Cross cultural and interdisciplinary}

The teams are formed from students of different disciplinary field and coming from different cultures. Within the team, the students (engineers, architects, and ergonomics) shall bridge the cultural gap to understand quickly each other. Outside the team, they have to hear and understand the diverse reasons and values of company employees.

The teachers also come from different countries and different disciplinary fields and exchange each other about project and students works that is often very productive and stimulating.

\subsection{Intensive}

During the CPW duration, the students' teams work only on CPW. That means they have only one goal when in traditional university life they works during the semester on 5 to 7 courses that belong to different disciplinary field. The time constraint reinforces the intensive background.

\subsection{From diagnostic to project}

Usually the ergonomics surveys stop to requirements and don't investigate the Design (ErgoDesignForum symposium). This is logic regarding the skills of ergonomics and engineering designers and also the traditional project management process.

In $\mathrm{CPW}$ model the ergonomics and engineers are working in the same time that introduce an interactive games of questions answers between diagnosis elements and project elements. Like this diagnosis involve (integrate) the possible responses and possible responses have been evaluated regarding the diagnosis. So CPW could be seen as a concurrent engineering process applied to well being at work.

\subsection{Modeling}

The CPW students teams are asked to realize mockups. The work has began with the observation of industrial reality, and after the identification of pertinent issues and diagnostics, estimating causes and consequences using theoretical knowledge, the mockup time is dedicated to focus on solution appropriate to industrial world. For the IPOD generation, it's important to get in touch and design with 
material. Furthermore, a mockup is easier to compare with reality than a blueprint would be, so all stakeholders (operators, engineers, managers, customers...) can understand how the students projects meet their interests.
At this point, a question arise: According to the time constraint ( 2 weeks), is it believable that students' team can produce valuable result even they are supported by experience issued from academic staff and professional?

\section{Implementation and results}

Table 1

Realized CPWs

\begin{tabular}{|c|c|c|c|}
\hline Date & $\begin{array}{l}\text { Industrial } \\
\text { sector }\end{array}$ & Country & University; Organization \\
\hline 20 & $\begin{array}{l}\text { Aseptic } \\
\text { industry }\end{array}$ & France & $\begin{array}{l}\text { Compiegne University of technology, Architecture school of Cler- } \\
\text { mont Ferrand, INRS }\end{array}$ \\
\hline $06^{20}$ & $\begin{array}{l}\text { Meat in- } \\
\text { dustry }\end{array}$ & France & $\begin{array}{l}\text { Compiegne University of technology, Architecture school of Cler- } \\
\text { mont Ferrand INRS }\end{array}$ \\
\hline 20 & $\begin{array}{l}\text { Wood in- } \\
\text { dustry }\end{array}$ & France & $\begin{array}{l}\text { Compiegne University of technology, Architecture school of Cler- } \\
\text { mont Ferrand, University of Chalmers Goteborg, University of Cluj } \\
\text { and Bucharest }\end{array}$ \\
\hline $0^{20}$ & $\begin{array}{r}\text { Frozen } \\
\text { vegetable }\end{array}$ & France & Compiegne University of technology, Medical faculty of Amiens \\
\hline 08 & $\begin{array}{l}\text { Old peo- } \\
\text { ple home }\end{array}$ & Sweden & $\begin{array}{l}\text { Compiegne University of technology, Architecture school of Cler- } \\
\text { mont Ferrand, University of Chalmers Goteborg, University of Cluj } \\
\text { and Bucharest }\end{array}$ \\
\hline 09 & $\begin{array}{l}\text { Wood in- } \\
\text { dustry }\end{array}$ & Brazil & $\begin{array}{l}\text { Compiegne University of technology, Parana's Federation of indus- } \\
\text { tries (FIEP) }\end{array}$ \\
\hline 09 & $\begin{array}{l}\text { Car manu- } \\
\text { facturer }\end{array}$ & $\begin{array}{l}\text { Roma- } \\
\text { nia }\end{array}$ & $\begin{array}{l}\text { Compiegne University of technology, Architecture school of Cler- } \\
\text { mont Ferrand, University of Chalmers Goteborg, University of Cluj } \\
\text { and Bucharest }\end{array}$ \\
\hline $10^{20}$ & $\begin{array}{l}\text { Mechani- } \\
\text { cal Industry }\end{array}$ & Brazil & $\begin{array}{l}\text { Compiegne University of technology, Parana's Federation of indus- } \\
\text { tries (FIEP) }\end{array}$ \\
\hline 20 & $\begin{array}{l}\begin{array}{r}\text { Lead re- } \\
\text { cycling }\end{array} \\
\end{array}$ & France & Compiegne University of technology \\
\hline 20 & $\begin{array}{l}\text { Construc- } \\
\text { tion industry }\end{array}$ & Brazil & $\begin{array}{l}\text { Compiegne University of technology, Parana's Federation of indus- } \\
\text { tries (FIEP) }\end{array}$ \\
\hline
\end{tabular}


Table 2

Results Communication-evaluation

Table 3

Activities described as functions, duration, conséquences, probability and risk

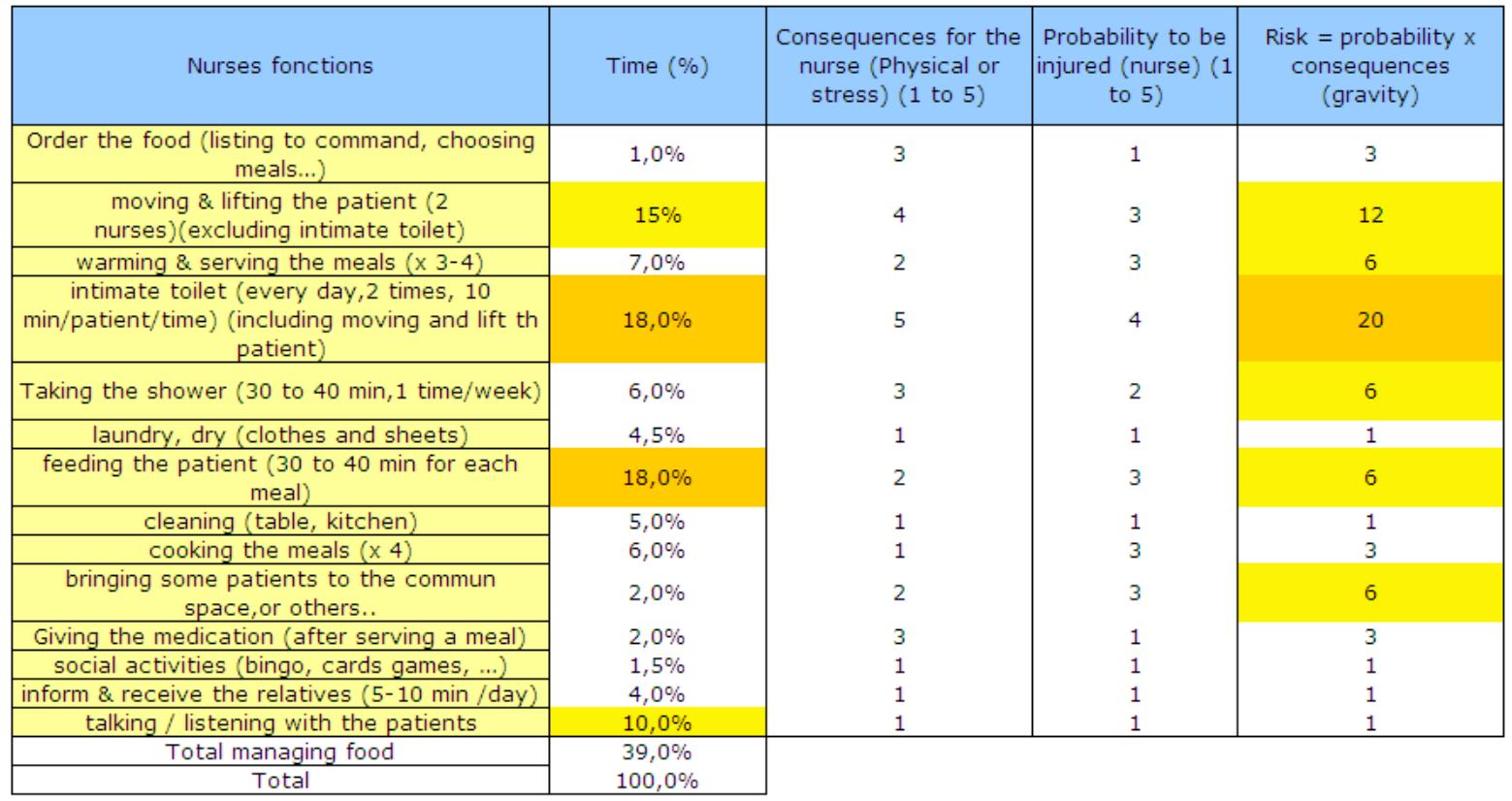


Table 4

Gains for patient : Actions in order to improve the customers' satisfaction

\begin{tabular}{|c|c|c|c|}
\hline Patient actions / day & $\begin{array}{l}\text { Life necessity (1 } \\
\text { to } 5)(60 \% \text { of } \\
\text { importance) }\end{array}$ & $\begin{array}{l}\text { Life \& pleasure ( } 1 \text { to } \\
\text { 5) ( } 40 \% \text { of } \\
\text { importance) }\end{array}$ & $\begin{array}{c}\text { patient's gain }=60 \% \text { Life } \\
\text { necessity }+40 \% \text { life } \\
\text { pleasure }\end{array}$ \\
\hline Taking meals & 5 & 4 & 4,6 \\
\hline being moved \& lifted & 4 & 1 & 2,8 \\
\hline changing clothes & 3 & 4 & 3,4 \\
\hline Taking medication & 5 & 2 & 3,8 \\
\hline being cleaned by a nurse & 4 & 3 & 3,6 \\
\hline Being fed by a nurse & 5 & 2,5 & 4 \\
\hline walking & 5 & 2 & 3,8 \\
\hline looking, hearing and smelling outside & 4,5 & 4 & 4,3 \\
\hline social activities (bingo, cards games, ...) & 2 & 4 & 2,8 \\
\hline meeting doctor & 5 & 5 & 5 \\
\hline talking/listening with the nurses, relatives, & 3 & 5 & 3,8 \\
\hline
\end{tabular}

Table 5

Plenum example : existing situation and new design proposed by students

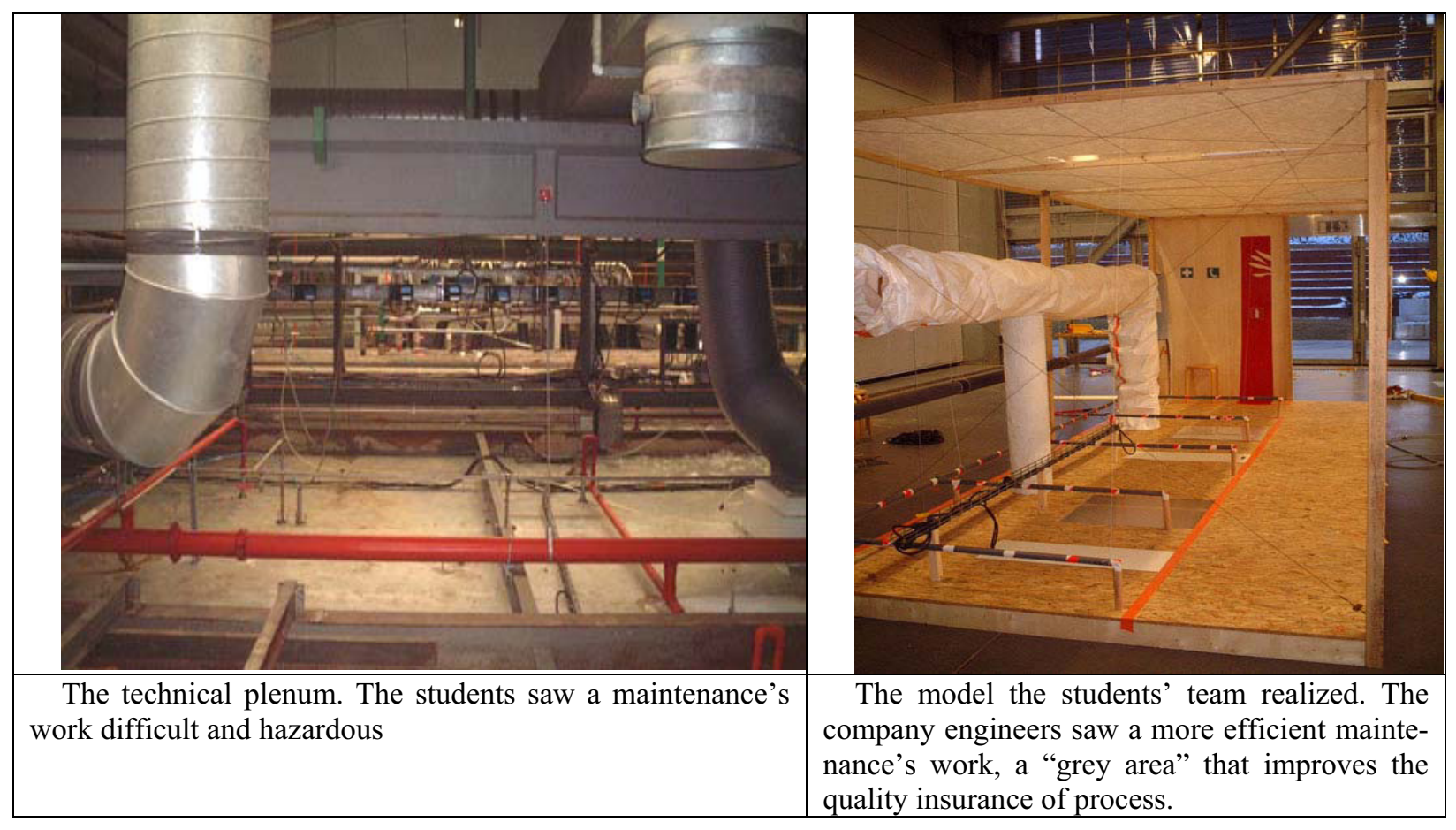




\section{Results}

\subsection{Communication-evaluation ( see table 2)}

Stephan Marsina (2) gave an explanation of comunication difficulties as a result of "hierarchical communication gaps" and "functional communication gaps" and study how project management could overcomes theses gaps. There are probably other reasons to explain the communication difficulties, but we can use this illustration to describes part of the students' work

They go from island to island where they communicate with the persons situated in the island. We noticed several time their communication efficiency due to team interdisciplinary and to specific skill of young student to understand what different teachers say. So they create bridge over these communication gaps.

Since we have asked them to consider the occupational risks, they collect employees' opinion about these risk and how the employees evaluate them. We can see in the following table two sort of information: The duration of each task which is very important for the operational cost, and the risks and difficulties associated with each tasks (see tables 3 and 4). This example shows a synthesis that takes in account the interest of three « islands ».

\subsection{Prevention through design: Example: Technical plenum 2005 ( see table 5)}

Many industrial processes are now performed in "clean areas" free of dust and eventually free of biological agents. Above the clean area is the technical plenum containing equipment that support processes realized in the clean area.

Looking at these factories, you can see the advanced manufacturing where the clean products like medicine or electronic devices we need are produced.

Laure Mulot, Claire Dreyfus, Stéphanie Dumas, Camille Tranchand have had another insight: The equipments located in the plenum are essential for the main process but their maintenance is difficult and dangerous, which raise the following questions: How can we make the maintenance work in the technical plenum easier and safer?

\subsection{Innovation}

The risk approach leads to innovations in several manners:
Innovative designs. For example the technical plenum design showed through a model didn't exist before in the company where CPW was realized.

New ideas and new project objectives: Within old people home context, as we saw it previously student mixed the quality (customers' interests), the operational costs (durations of tasks) and the employees' occupational risks. These results indicate what kind of innovation should be targeted: Innovations reducing long and hazardous task without decrease what is important for the patients.

\subsection{Company benefits}

First a meaningful part of CPW teams solutions are implemented by companies (Students' report and mockups show how it would be interesting (and profitable)to do it, and that it is feasible but the implementation require detailed engineering realized by experimented professionals ).

Second, since the employees' judgments on risks prevention and wellbeing are embodied in solution, the implementations by the companies improve the cohesion and solidarity of personnel.

\subsection{Academic benefits}

The repeated two week CPW progressively encourages interdisciplinary activities from teaching to searching.

We have introduced in lectures several issues as innovation resulting of risk analysis or as prevention through design with case study resulting from CPW.

\subsection{Students' benefits}

The most interesting result is the difference between was student think before the CPW and what they think after. The questionnaire results are particularly significant for the score to questions such as the importance of safety and well being at work, its interest, the will to include it in their future job.

After a CPW, the majority of student considers that it is useful and important to take in account the judgment of the different categories of employees (specifically the operators).

\section{Conclusion and discussion}

Our fundamental opinion is as pedagogical method CPWs are a complement to traditional teaching. The two learning methods help each other. On one hand the skills that students acquired though their different 
disciplinary courses have facilitated their work with operators, engineers and managers, on other hand CPW helps students to understand the importance of fundamental knowledge.

CPW produces quickly results and solutions appropriate to the company where it has take place. Some of these solutions are implemented by the company employees. Some other requires external proficiencies. In this case, $\mathrm{CPW}$ indicates to companies management witch proficiencies are required. The series of CPW experiments has shown that more the employees of a company are involved in CPW; more the result CPW teams are profitable for the company and the employees. John (3) goes on to acknowledge that education and schooling are instrumental in creating social change and reform. Our result would indicate that $\mathrm{CPW}$ could be instrumental for launching co-evolution of the personnel. This coevolution would result in activities changes and processes. In "Bonduelle" a company producing frozen vegetable, where a CPW stand in 2008, employees say that "the students gave us a new impulse". In fact, the company management has quickly decided to realize the students' project obviously short payback period $^{1}$, and after that they (managers, engineers, and operators) implemented prevention through design in the different project of factory modernization. The results of Jussi Kantola, Hannu Vanharanta, and Waldemar Karwowski (4) suggest that the creative tensions of employees could be linked with their performances. So it would be interesting to study both the evolution of creative tension and the technical or organizational change in a company after a CPW (5).

At the initial step the goal was to introduce a motivating learning system to increase engineering students awareness to risk prevention and well being at work. Our hypothesis was to involve the students in project learning system and the results validate totally this hypothesis.

An important point is that the today young graduates will get more and more responsibility with the years. So we could also expect that the fifteen days of CPW gives them an impulse with positive consequences for this next future. of both the value of better productivity, and the value of occupational risk reduction.
- Considering and observing facts

- Continuous learning to understand others ideas whatever disciplinary or cultural fields they come from.

Although students have systematically showed a high approval rate, we don't show evidence of a persistent student's change that would result from CPW.

\section{References}

[1] J., Piaget. Réussir et comprendre. Paris : P.U.F., 1974.

[2] Stephan, Marsina. Development of project orientation helps organization improve communications not only on projects. Girona: Evolute Symposium "Developing human and company performance", 2011.

[3] Dewey, John. Democracy and Education: An introduction to the philosophy of education. 1916.

[4] Jussi Kantola, Hannu Vanranta, Waldemar Karwowski Link between operators' creative tension and the performance data of shifts..

[5] M. Le Chapellier, P.H. Dejean. Evolute approach and CPW approach. Girona: Evolute Symposium "Developing human and company performance", 2011. 